\title{
MIDAS
}

Museus e estudos interdisciplinares

$3 \mid 2014$

Varia e dossier temático: "Museos y participación biográfica"

\section{Escolares nos museus: Ensaio do novo público como ato político de educadores intelectuais}

Students in museums. Practice of new audience as political act of intellectual educators

\section{Luciano Parreira Buchmann}

\section{OpenEdition}

\section{Journals}

\section{Edição electrónica}

URL: http://journals.openedition.org/midas/463

DOI: $10.4000 /$ midas.463

ISSN: 2182-9543

\section{Editora:}

Alice Semedo, Paulo Simões Rodrigues, Pedro Casaleiro, Raquel Henriques da Silva, Ana Carvalho

\section{Refêrencia eletrónica}

Luciano Parreira Buchmann, « Escolares nos museus: Ensaio do novo público como ato político de educadores intelectuais », MIDAS [Online], 3 | 2014, posto online no dia 09 junho 2014, consultado no dia 04 maio 2019. URL : http://journals.openedition.org/midas/463 ; DOI : 10.4000/midas.463

Este documento foi criado de forma automática no dia 4 Maio 2019

\section{cc) (†) (2)}

Midas is licensed under a Creative Commons Attribution-NonCommercial-ShareAlike 3.0 International License 


\section{Escolares nos museus: Ensaio do novo público como ato político de educadores intelectuais}

Students in museums. Practice of new audience as political act of intellectual educators

Luciano Parreira Buchmann

\section{Introdução}

1 É notória a transformação do campo da museologia e museus no Brasil nos últimos tempos. Surgiram novos cursos, pós-graduações na área, publicações, diversas instituições, houve inclusive, a criação do Instituto Brasileiro dos Museus (IBRAM) pelo Ministério da Cultura com editais e insumos. Apesar destes avanços positivos, a relação da educação formal com o museu, por diversos fatores, ainda é frágil e não pode ser comparada à realidade de países desenvolvidos. Estratégias que facilitem, promovam, vinculem a escola ao museu são pontuais e presentes em determinadas instituições das grandes cidades.

2 No tocante à educação nos museus, o cenário brasileiro contraria quase que completamente, as ideias contidas no artigo de Silva: «Enquadramento teórico para uma prática educativa nos museus» (2007). Os setores educativos, na maioria, são desconsiderados. Parece haver compreensão das administrações públicas e das direções das instituições de que as exposições são o suficiente. É como se o público fosse de especialistas. O número de museólogos é pequeno, os profissionais que atuam na educação nos museus são, frequentemente, professores de história ou de arte, sem uma posição teórica a fundamentar a prática.

3 Nessas instituições das cidades de pequeno e médio porte, a experiência do educando de baixo capital cultural, com pouco poder para partilhar no museu, de marcante, não tem 
muito. Apesar dessa perspetiva que parece contradizer o parágrafo inicial, é preciso compreender tratar-se de um país continental e de contrastes. Hoje, surge uma política cultural federal com alguma atenção aos museus e às escolas, com mecanismos de trânsito entre a área cultural e a educação. Então, o futuro é promissor.

Neste panorama de transformação do país, na cidade de Curitiba (Paraná, Brasil), as visitas de grupos escolares carecem de forte desejo dos professores ou professoras.

5 Segundo Valdez (cit. por Juanola e Colomer 2005), os museus têm possibilidades educativas nos âmbitos formal, não formal e informal do ensino que dependem do uso que dele se faça, do público que os utilize, das condições da visita, dos conhecimentos prévios, dos interesses e dos objetivos, podendo o museu ser tomado como instrumento de aprendizagem. Nesse sentido, Juanola e Colomer $(2005,35)$ compreendem que:

El museo debe ofrecer experiencias de aprendizaje informal que deben inserirse en el tejido escolar de una forma transversal, proporcionando al profesor los instrumentos necesarios para que puedan aprovechar los recursos que ofrece el museo y adaptarlos a su trabajo diario en el aula.

6 A perspetiva da educação com o museu que defendo, tem na professora ou professor um papel fundamental: mediar o conhecimento apresentado na escola com a experiência no museu. Coisa que não é simples. Para os outros visitantes, a presença de grupos escolares desperta empatia, mas poucos atribuem o evento aos docentes. Evidentemente que os estudantes não chegaram lá sozinhos, foram levados. Quem os levou? O que houve para que isso acontecesse? Poucos imaginam que o simpático encontro de crianças com a arte seja uma conquista de guerra travada pela professora ou professor dentro da escola.

7 Martins e Picosque (2008) referem-se à visita ao museu como «expedição instigante»; e estão certas, pois, com ela, muitas coisas podem ser descobertas. Essa viagem começa na escola e pode continuar com muitos desdobramentos. Mas, por outro lado, no caso do docente, a expedição é digna de Indiana Jones.

Uma saga que se inicia no convencimento de diretoras, pedagogas e colegas de que com a expedição os estudantes aprenderão algo; que é fundamental ver arte e, ainda, que o sucesso dessa ação depende da companhia dos colegas e das suas aulas. ${ }^{1}$ Além disso, existe na escola uma certa disputa de recurso raro e fundamental: o transporte. A suposição de insucesso da expedição faz a escola analisar se ações mais populares como uma ida ao parque, ao jardim zoológico, não seriam mais adequadas ao investimento.

Vencidos os preliminares é hora das aulas preparatórias, fundamentais para o desenvolvimento da visita ao museu e, nem sempre, infelizmente, são consideradas importantes pelos profissionais. Ao invés de conceitos e experiências que aproximem o estudante do que verão na visita, muitos consideram suficientes simples recomendações quanto ao comportamento naquele local, visão que, segundo B. Freire $(1992,96)$ impõe uma situação de distanciamento do aluno-visitante/objeto; são «recomendações disciplinares e definem, para o estudante, as regras de uso do espaço museu, a partir de proibições, como não tocar, não falar alto, não pisar forte.»

10 No museu, o mar de rosas não acontece; pelo contrário, os profissionais vivem momentos de tensão. Em minha perspetiva, esta questão relacionada com a educação e com o museu brasileiro é pouco analisada; e este estado, que considero tenso, pode ser justificado por três motivos: o significado do museu para os estudantes, a falta de autonomia e autoridade das professoras e professores e, por fim, a sensação de julgamento que oprime tais profissionais. Para esclarecer a questão, analiso cada um dos motivos. 
11 A questão do significado do museu para os estudantes está ligada ao imaginário construído por via do cinema e dos desenhos animados: cenário composto de armaduras, globos terrestres, bibliotecas com passagens secretas, animais empalhados, pó, teias de aranha, retratos que vigiam os visitantes e sábios reclusos, colecionadores estranhos ou cientistas loucos e os tão esperados esqueletos de dinossauros. Todos estes ingredientes apontam curiosidade, conhecimento e mistério, e pode-se supor que a matriz dessa imagem sejam os antigos museus de história natural. É certo que não se pode generalizar, muitos estudantes já visitaram museus contrapondo tal descrição.

Ainda é importante pensarmos que para a imensa maioria dos estudantes a aula externa é um evento inesquecível; uma absoluta exceção nas suas vidas escolares. A excecionalidade transforma a experiência numa festa para quem amarga metade dos 200 dias do ano sentado, em sala fechada, preso ao seu bairro. E, assim, tudo é novidade, contrariando a contenção escolar que aprendeu a atribuir às aulas. Esse fator, a excecionalidade, traz consigo a novidade e a descoberta, o que, segundo Silva (2007) tem dois lados e um duplo efeito: motiva a aprendizagem podendo também provocar a dispersão. Comum, são crianças.

13 No museu, o comportamento exigido é para os estudantes um contrassenso, afinal, não estão na escola: tomaram o ônibus para um lugar diferente e, ao invés da professora, quem agora conversa com eles é uma outra pessoa. Como exigir que diferenciem essa aula externa de um passeio e, ainda, de que modo não compreender que estejam tão excitadas? Há barulho, empurra-empurra, cutucões, delações, risadas, às vezes, choro. 0 silêncio e a ordem não cabem na equação.

14 Além destes fatores, faltam para o estudante os significados sobre o que verão na maioria dos museus. Não estamos tratando, no momento, dos museus de história natural. A ausência de significados, em minha opinião, dá-se pela falta de conhecimento sobre o que será visto, o que faz a educação no museu depender da ação previamente desenvolvida na escola.

O segundo motivo, da tensão do professor, é a falta de sua autonomia em relação ao museu e sua autoridade no que se refere à arte. Ainda não temos professores que se apoderem da instituição como instrumento educacional e que se coloquem como sujeitos ativos na visita ${ }^{2}$, seguros nos seus objetivos e na relação destes com os objetos expostos. ${ }^{3}$ Por esta razão delegam a orientação do grupo aos monitores ou mediadores que normalmente são académicos, não estão ainda formados, são jovens, desconhecem a realidade da escola, nunca viram os estudantes e os levam para lá e para cá, mostrando o museu. A falta de autonomia impede os professores de mostrar esse género de arte ou aquele, estas salas e não aquelas, estes assuntos e não outros, escolher em relação ao currículo e sua abordagem, o que atingiria, enfim, o objetivo da visita.

16 A sensação de julgamento que vivem os professores no museu é o terceiro motivo, que se apresenta para o estado da educação em museu para escolas. Decorre de vários fatores: um deles é o acima exposto, que se soma à ausência de autoridade sobre os conteúdos e que os fragilizam. São ainda os julgamentos que partem de pessoas que criticam o comportamento dos estudantes, ou, ainda, do necessário movimento do professor ao interceder no burburinho e chamar a atenção do grupo, coisa do quotidiano de sala de aula e da liderança disciplinar. Este olhar negativo toma dois posicionamentos para julgar: ou o/a professor/professora está cerceando os processos criativos dos estudantes, ou eles são arruaceiros por descuido dele/a. Não são analisados os conhecimentos que 
estes profissionais ajudaram a construir em sala de aula, o seu esforço para promover a visita, a sua frustração frente ao modo como tudo se encaminhou, muito contrário ao que desejavam.

Não é raro que, ao fim da expedição, os professores retornem à escola sem voz e exaustos. O corpo parece ter lutado. Neste sentido, P. Freire $(2005,92)$ tem uma reflexão interessante: «Meu corpo consciente está sendo por que faço coisas, por que atuo, por que penso» e o corpo «deseja, aponta, anuncia, protesta, se curva, se ergue, desenha e refaz o mundo», apesar de cansado.

Infelizmente, o investimento e o desgaste na epopeia fazem os professores pensarem: «Nunca mais!». Passada essa primeira sangria, na escola surgem comentários dos estudantes de outras turmas e que não foram ao museu: já sabem o que lá foi visto, perguntam e interessam-se; a produção plástica do grupo que participou da expedição teve um sobressalto resultante do impacte frente a frente com a obra e existe uma estranha diferença na relação entre os estudantes e a/o professora/professor. Uma certa cumplicidade. É como se juntos tivessem pulado o muro da escola para nadar num rio. Algo aconteceu e o grupo não sabe externar em palavras.

Da parte dos museus existe uma certa ideologia de que os estudantes e as/os professoras/ professores são bem-vindos e até aquelas instituições que cobram o ingresso liberam-nos para as escolas públicas. Mas, esta ideologia boa moça é falaciosa, as coisas não são bem assim. Como disse Bourdieu e Darbel (2003, 71):

Cada indivíduo possui uma capacidade definida e limitada de apreensão da "informação" proposta pela obra, capacidade que depende de seu conhecimento global (por sua vez, dependente de sua educação e de seu meio) em relação ao código genérico do tipo mensagem considerado, seja a pintura em seu conjunto, seja a pintura de tal época, escola, ou autor. Quando a mensagem excede as possibilidades de apreensão do espectador, este não apreende sua "intenção" e desinteressa-se do que lhe parece ser uma confusão sem o menor sentido, ou um jogo de manchas de cores sem qualquer utilidade.

20 A estrutura social faz com que sejam bem-vindos os que sabem o que lá dentro está. Quem traz estudantes sem o privilégio de herdar de seus pais a disposição culta (Bourdieu e Darbel 2003) para ver arte, e que, por isso, não percebem sentido algum naquilo tudo e badernam no templo, é de certa forma um incómodo.

21 Tanta adversidade à/ao professora/professor e esta prática servindo de máscara a uma ideologia, por que defendê-la? Não deveríamos concluir que se o museu é para quem já tem conhecimento, para quê insistir? Não seria mais fácil deixar a visita ao museu de lado, aceitar a ordem das coisas e levar os estudantes onde se sintam bem e possam desfrutar de um passeio? Não seria preferível esperar que as políticas públicas sejam estipuladas favorecendo a conquista do património e consequente sentimento de pertença pela população, ao invés de darmos um murro em ponta de faca?

Por que então vale a pena contrariar tudo o que dissemos acima? Qual a justificativa para incentivar que professores/professoras visitem museus com os seus estudantes e nessa expedição mantenham-se como verdadeiros mediadores que são? Apesar de esta prática educacional ser infimamente pequena em relação às outras, devido ao fato da maioria dos museus estar localizada nos grandes centros urbanos e às dificuldades já apresentadas, há professoras/professores que nela insistem, contribuindo na transformação do cenário. Houve sensível diferença entre os campos escola e museu. É inegável que no Brasil o número de museus e os cursos de museologia vêm crescendo; as licenciaturas estão mais 
atentas à parceria escola/museu; diversas publicações no campo do ensino da arte relativa ao tema tornaram-se mais frequentes, o que gera positiva pressão para que as aulas externas se tornem habituais. Entretanto, esta movimentação ainda não alterou a situação dos professores e professoras. É possível imaginar inclusive certa penalização imposta aos mesmos, caso a obrigatoriedade da educação no museu viesse a ocorrer, se não for pensada a diversidade, os padrões socioeconómicos, as diferentes realidades interior/capital e a formação profissional. Além destes importantes complicadores, a obrigatoriedade removeria da estratégia educativa alguns ingredientes oriundos da subjetividade.

24 A pretensão deste artigo é contribuir para que aconteçam mudanças na relação, tão complexa, de educar/mediar para a arte; uma tentativa de alterar o que vem sendo mantido e provocar a reação de professores/professoras para colocarmos o bonde do mundo em outros trilhos, como disse P. Freire (2005), convencer professores e professoras do seu papel intelectual e político, para agirmos contra a privação do que é público e promovermos o sentimento de pertença do património.

\section{É possível fazer diferente}

Para defender esta posição, as ideias de Arendt (2005), Brandão (2002) e Giroux (1997) e alguns dados recolhidos, a partir de famílias de estudantes de escolas públicas a respeito de seu consumo cultural, contribuem para o fortalecimento do argumento e para pensarmos nas razões da inclusão de visitas aos museus no planejamento das aulas.

Arendt (2005) não foi professora, nem tampouco museóloga, era filósofa política. O seu pensamento trouxe críticas que são pertinentes e servem para refletirmos sobre o que nos fez ser o que somos: de onde viemos, o que de lá trouxemos, como a vida coletiva nos moldou, o que recebemos como legado e de que forma o legamos; enfim, a responsabilidade do nosso papel na educação, sempre tenso entre o ontem e o amanhã.

Para a autora a essência da educação é a natividade. É por meio dela que viemos ao mundo, isto é, recebemos todas as coisas que nos constituíram pela tradição. E dessa forma saímos da esfera do mundo privado do lar, o mundo quentinho em que estamos protegidos da tirania do grupo, para sermos introduzidos em um mundo velho, préexistente: o mundo público, mundo do clarão, da celebridade, das disputas e que requer o posicionamento político para fazermos mudanças.

Não cabe neste contexto estender-me com a razão da crise na educação, que a filósofa tão bem apresenta ${ }^{4}$, tomo apenas o segundo dos pressupostos da sua análise: a perda da autoridade dos professores e das professoras nas suas próprias matérias, causada pela negligência na formação docente em decorrência do problema político relativo à cultura americana, da pedagogia influenciada pela psicologia moderna e pelos princípios pragmáticos. A frase da filósofa é esta:

[...] o professor não precisa conhecer sua própria matéria, não raro acontece dele encontrar-se apenas um passo à frente de sua classe em conhecimento. Isso quer dizer, por sua vez, que não apenas os estudantes são efetivamente abandonados a seus próprios recursos, mas também que a fonte mais legítima da autoridade do professor, como a pessoa que, seja dada a isso a forma que se queira, sabe mais e pode fazer mais que nós mesmos, não é mais eficaz. (Arendt 2005, 231) 
undo motivo da tensão vivida no museu pelos docentes, apresentado anteriormente é que na exposição as obras de arte não são compreendidas como continente da dimensão humana e de conteúdos específicos da linguagem visual.

A ideia de Arendt (2005) é que a instituição entre o mundo privado e o público seria a escola, na qual o estudante poderia ensaiar a vida pública protegida pelo adulto/professor e a sua autoridade nos conhecimentos do mundo velho. Essa autoridade e a cautela sobre o ensaio de quem chega ao mundo público é a dimensão política do trabalho do educador. É isso que podemos trazer para pensar na relação professor/escola/museu. Para a autora:

A educação é o ponto em que decidimos se amamos o mundo o bastante para assumirmos a responsabilidade por ele e, com tal gesto, salvá-lo da ruína que seria inevitável não fosse a renovação e a vinda dos novos e dos jovens.

A educação é, também, onde decidimos se amamos nossas crianças o bastante para não expulsá-las de nosso mundo e abandoná-las a seus próprios recursos, e tampouco arrancar de suas mãos a oportunidade de empreender alguma coisa nova e imprevista para nós, preparando-as em vez disso com antecedência para a tarefa de renovar um mundo em comum. (Arendt 2005, 247)

\section{Dimensão política}

Essa renovação do mundo não é uma das coisas mais nobres a fazermos? Não se trata de ação comprometida com o social e, assim, ação política para a mudança? o sujeito que compreende essa dimensão da educação, e a vive na prática, como poderia ser visto?

A dimensão política da educação é um dos temas de Giroux (1997), que o pedagogo crítico americano discute em seus textos. $O$ autor defende a posição do professor/professora em ocupar o papel de intelectual.

É interessante, antes de apresentar as suas ideias, determo-nos sobre as implicações dessa definição: o trabalho do intelectual é da ordem do simbólico e são muitas as suas expressões, a filosofia, a literatura, a arte. $O$ acesso aos bens simbólicos dá-se também pelo museu. Nesse contexto podemos compreender o trabalho intelectual do professor/ professora, o uso da memória social presente nos artefatos, atualizando-a como dispositivo para novas criações/interpretações.

As nossas memórias contam experiências individuais, que pelas artes e pelos artefatos preservados nos museus ligam-nos à humanidade quando os significamos/resignificamos. Ao pensarmos essa operação na estrutura do estudante, percebemos a necessidade da mediação do educador. Um trabalho intelectual que une o conhecimento apresentado na sala de aula de arte ao que é visto no museu; nas palavras de Ortiz $(2003,139)$ seria a sutura entre o que as pessoas vivem nas suas experiências individuais e o universal. Neste caso, trata-se da construção de uma ponte entre a subjetividade e o universo simbólico, um trabalho sensível e intelectual.

Voltando à ideia de Giroux $(1997,186)$, os educadores são compreendidos como intelectuais por serem mediadores, legitimadores e produtores de ideias e práticas sociais e, também, por cumprirem «uma função de natureza eminentemente política». No seu papel transformador caberia a esses intelectuais «desenvolver e trabalhar com movimentos fora dos contornos limitantes das disciplinas», tomando «a sociedade como uma grande escola» (188).

$\mathrm{O}$ autor defende a aquisição de linguagem, a da arte ou qualquer outra ${ }^{5}$, «como uma forma de aprendizagem que não apenas instrui os estudantes quanto às formas de "nomear" o

MIDAS, 3 | 2014 
mundo, mas também lhes introduz em relações sociais particulares», e é nesse sentido que podemos pensar nas ferramentas de leitura como instrumento de acesso aos bens simbólicos para a inclusão no direito de conhecer o campo cultural. Ou seja:

Tornar o pedagógico mais político significa inserir a escolarização diretamente na esfera política, argumentando-se que as escolas representam tanto um esforço para definir-se o significado quanto uma luta em torno das relações de poder. Nessa perspetiva, a reflexão e ação críticas tornam-se parte do projeto social fundamental de ajudar os estudantes a desenvolverem uma fé profunda e duradoura na luta de superar injustiças políticas e sociais, humanizarem-se ainda mais como parte da luta... reconhecer a necessidade e aperfeiçoar seu caráter democrático e qualitativo para todas as pessoas, significa compreender as pré-condições necessárias para lutar por ela. (Giroux 1997, 163)

Enfim, tornar o pedagógico mais político e o político mais pedagógico faz dos professores/ professoras intelectuais transformadores, nessa batalha contra o monopólio sobre o que é público e a privação do uso do museu pela maioria.

\section{Para entender as relações entre o museu e a escola: pesquisando o contexto}

38 A perspetiva que defendo da transformação de compreensão dos professores e professoras como agentes políticos na relação escola/museu pode ser fortalecida com a experiência que vivi junto ao projeto Ampliando Horizontes da Secretaria Municipal da Educação de Curitiba (SME) desenvolvido ainda na atualidade. No projeto, educadoras/ educadores, professoras/professores e pedagogas da Educação Infantil e Ensino Fundamental têm a oportunidade de receber informações sobre o património cultural, os museus e temas relacionados. Como parte da metodologia adotada, no fim do curso, os inscritos devem propor ações educativas junto do património, seja levar os estudantes a museus, ver monumentos na cidade, apresentar relações do saber/fazer.

No curso que lecionei no projeto Passeio, oba! Mas que passeio é esse? propus uma pequena pesquisa de campo por considerar insuficientes as informações da teoria social ou a apresentação de metodologias para a prática docente nas exposições dos museus, sem apresentar dados da realidade dos estudantes e das suas famílias a respeito do seu tempo livre e do seu consumo cultural.

Para isso, a SME encaminhou os profissionais que se inscreveram no curso para um questionário por mim desenvolvido, que buscava revelar estes hábitos, bem como as sugestões para aulas externas que consideravam mais importantes. As questões foram: Quais as atividades que vocês costumam fazer no final de semana e com qual frequência? Caso as instituições planejassem atividades externas com os estudantes, o que os senhores nos sugeririam? Enumere, da lista abaixo, quatro ações que você consideraria mais importantes a serem desenvolvidas, em ordem de importância.

No ano de 2010 recebemos a tempo, para a tabulação dos dados, 110 questionários, dos quais 103 traziam todas as respostas. ${ }^{6}$ Das 110 famílias, 63 consideraram como ação mais importante a ser desenvolvida pela escola a prática desportiva, em contraste com quatro famílias que sugeriram o museu como uma opção importante. Na análise dos hábitos no tempo livre destas quatro famílias que indicaram o museu, todas assistem televisão (dois filmes em DVD), limpam a casa, frequentam a igreja, visitam a família; de vez em quando 
vão ao parque. Estas famílias disseram que eventualmente passeiam no centro da cidade ou nos shoppings centers e que, nunca, nunca vão ao cinema, ao teatro e ao museu.

Vale a pena transcrever o que disse uma mãe de 27 anos, com o segundo grau incompleto, que além de assinalar as alternativas fez o seguinte comentário ao responder às suas atividades de fim de semana: «Na Igreja é bom ir, mas não dá para esquecer que teatro e museu eles iriam gostar e principalmente aprender.» E nas sugestões esta mãe complementou as alternativas: «Dificilmente, as crianças praticam esportes, e é preciso, com certeza. O Lucas nunca foi a um museu nem em um teatro e ele iria aprender muito mais.»

43 É interessante pensar na questão. Eles não possuem esse hábito, mas reconhecem-no como prática importante para a escola, o que é um diferencial entre os 99 demais. Eles nunca vão e indicam que a escola leve seus filhos, mas isso seria eficaz? São diversos os depoimentos de estudantes relatando que levaram suas famílias ao museu após conhecêlo com a escola, mas essa excursão modificaria alguma coisa no consumo cultural das classes sociais?

Seria romantismo acreditar num impacte tão positivo nos hábitos familiares. No que esbarramos sempre é na barreira cultural que divide os estratos sociais no país. A mudança desta situação ocorreria num futuro distante, caso a esses estudantes fossem propiciadas visitas frequentes às instituições, o que modificaria a herança cultural de seus descendentes: legado que molda o herdeiro, comparável à osmose nas células como disse Bourdieu (1998) no que se refere ao domínio da língua e da cultura livre. Para o sociólogo é a herança cultural ao lado da inculcação escolar que garantiria a construção da disposição culta para a frequência de museus.

Bourdieu e Darbel $(2003,110)$ dizem que o «controle do código» sobre as obras expostas nos museus «pressupõe um treino metódico, organizado por uma instituição especialmente preparada para tal fim», ou seja, "o treino recebido na escola», eis a diferença na questão da construção desigual do capital cultural, ou seja, nas palavras da educadora Schlichta $(2009,33)$ : «A qualificação do olhar, ampliando os requisitos mínimos requeridos à apropriação da realidade humano-social», relevante tarefa que a educação para a arte desempenha.

\section{Conexões entre estudantes, o museu e a escola}

Mas o que é preciso ser feito para essa qualificação na escola? De que modo proceder? São as aulas preparatórias e os conceitos nela apresentados que dão estrutura para a experiência estética, e maior voz para a troca e a partilha no museu. Sem eles o olhar para a obra perde o tónus do significado. Faltam os instrumentos de análise ao iniciante, mesmo que rudimentares. Portanto, os aparatos conceituais precisam de ser adequados à compreensão do estudante para que ele vá além do que vê. Este elenco de conteúdos faz com que seja estabelecido o trânsito do estudante entre a arte, o museu e a escola; mas como estes mecanismos podem operar? De acordo com Schlichta $(2009,11)$ :

[...] devemos aliar o conhecimento dos códigos com a apreciação de obras; afinal, o aluno terá, assim, maiores possibilidades de apropriação das representações artísticas in loco. Por último, paralelo ao conhecimento técnico-artístico, ao contato direto com as obras ou com os livros de arte, catálogos de museus e exposições, parece-nos particularmente necessário o conhecimento e o contato, também, com a 
arte contemporânea, os novos procedimentos técnicos estilísticos, materiais e suportes alternativos, etc. precisam de prática para o uso nos museus, que, como sugere Darras $(2004,13)$, estudioso da mediação, são campos de batalha entre o visitante que não possui o conhecimento sobre o que está exposto e a posição de saber que a instituição ocupa. Para o autor, a mediação pode evitar essa guerra. E para praticar o uso deste arsenal a visita precisa mostrar aqueles saberes que não são ensinados em lugar algum senão na prática da visitação ou na aprendizagem tácita do exemplo dos pais: a etiqueta. consideramos não ter, que nos é invisível, incorporado ao longo da experiência como quem frui da arte. Esta aprendizagem vai desde a postura corporal, do silêncio 
contemplativo ou do sussurrar cúmplice, dos esquemas de observação desta ou daquela modalidade artística ou objeto exposto, que são respeitados pelos visitantes frequentes de espaços culturais. Trata-se, assim, de etiqueta que qualifica e distingue quem a tem como pertencente ao grupo. A cobrança da obediência a esses padrões é uma coerção que pune com a exclusão aquele que não a emprega, ou melhor, faz com que o sujeito se exclua.

Exemplo do uso desta etiqueta é o que vemos na plateia da música erudita. Os frequentadores dos concertos sinfónicos sabem o momento em que a orquestra será aplaudida sem tal informação no programa e, quando um desavisado bate palmas entre os movimentos da peça em execução, a hostilidade da plateia ao despreparo que estaria desrespeitando a concentração dos músicos é constrangedora. Isso é usar os garfos correspondentes aos pratos do banquete. Fazendo uma analogia, seria isso: a visita ao museu é um ensaio do público para ver arte com autonomia no futuro. Este ensaio conta com a proteção do/a professor/professora e nele o estudante sabe o que verá e como. Já está avisado do que vai ocorrer e dos porquês de portar-se conforme recomendado; pode praticar o uso dos códigos/etiqueta do grupo frequentador da instituição: afastar-se para ver a pintura ou as grandes dimensões, aproximar-se para perceber detalhes ou as modalidades que exigem os modos de precisão (gravura ou desenho); mover-se calmamente e deter-se no que chama a atenção; falar baixo com o parceiro de visita; ler os textos na exposição como integrantes da mesma e as informações anexas às obras; saber que o museu não é o edifício, mas que guarda e expõe um acervo público, não somente público: universal e, por isso, pertencente a todos e merecedor de respeito.

Infelizmente alguns professores/professoras esquecem ou desconhecem, que entender o museu como extensão da escola é uma «opção teórica e portanto política» como bem nos faz pensar Ramos $(2004,15)$ quando usa as palavras de P. Freire: «É tão impossível negar a natureza política do processo educativo quanto negar o caráter educativo do ato político». Nesta mesma direção, Brandão $(2002,169)$ entende que a educação, como prática que toma as relações entre as pessoas e a cultura, possui duas dimensões políticas; a primeira «no sentido de que todo saber emana de polos de poder e corresponde a seus interesses, ou, então, afirma-se como a possibilidade de transgredi-los», e a segunda, de que «o saber é, em si mesmo, uma dimensão do poder.»

A proposição de aulas em museus ou nas expressões do património são ações políticas, interferem e transformam a realidade. $O$ simples fato de quem nunca visitaria o museu por si próprio tê-lo feito pela escola, mesmo que não venha a tornar-se um consumidor cultural, implicou no uso do instrumento cultural, caríssimo, que indiretamente ajuda a manter. Esta visita pode ser a oportunidade de, quem sabe, escolher o museu como mais uma forma de entretenimento.

Retornando um pouco ao início do artigo, referi que a visita ao museu altera a relação entre estudantes e a/o professora/professor, baseado em diversos relatos: uma professora que tive a honra de orientar em projeto de ensino contou-me que depois de visita a um museu os estudantes aguardavam-na no portão da escola para saber o que teriam na programação da semana. Nas minhas memórias de professor, lembro-me dos meus alunos descreverem coisas do museu aos colegas de outras turmas, adiantando o que estes veriam e, orgulhosos como assistentes, pediam-me que confirmasse os seus relatos: - Né, Luciano!

No que acredito é que a aproximação estudante/professor encerra um significado: os estudantes formulam essa expressão mista de gratidão e de reconhecimento profissional, coisa cifrada que diz: - Obrigado por ter feito isso por nós e desculpe a canseira! - É 
possível que, mais maduras, formulassem outro discurso, diriam que o evento teve importância na história das suas vidas: - Eu estive aqui com a escola, na aula de arte.

\section{BIBLIOGRAFIA}

Arendt, Hannah. 2005. Entre o Passado e o Futuro. São Paulo: Perspetiva.

Bourdieu, Pierre, e Alain Darbel. 2003. O Amor Pela Arte: Os Museus de Arte na Europa e Seu público. Porto Alegre e São Paulo: Zouk e Editora da Universidade de S. Paulo.

Bourdieu, Pierre. 1998. “A Escola Conservadora: As Desigualdades Frente à Escola e à Cultura.” In Escritos de Educação, organizado por Maria Alice Nogueira, e Afrânio Catânio, 41-64. Petrópolis: Vozes.

Brandão, Carlos Rodrigues. 2002. Educação Como Cultura. Campinas: Mercado das Letras.

Darras, Bernard. 2004. "Entretiens Avec Jean Caune, Bernard Darras et Antoine Hennion.” In Mediation e Mediateurs, coordenado por Marie Thonon. Paris: Éditions de l'Harmattan.

Freire, Beatriz Muniz. 1992. “O Encontro Museu/Escola: O Que Se Diz e o Que Se Faz.” Dissertação de mestrado, Departamento de Educação da Pontificia Universidade Católica do Rio de Janeiro.

Freire, Beatriz Muniz. 1996. “Museu/Escola: Etnografia de um Encontro.” In O Museu em Perspetiva . Encontros e Estudos 2, 9-22. Rio de Janeiro: Ministério da Cultura, Funarte.

Freire, Paulo. 2005. A Educação na Cidade. São Paulo: Cortez.

Giroux, Henry. 1997. Os Professores como Intelectuais: Rumo a uma Pedagogia Crítica da Aprendizagem. Tradução de Daniel Bueno. Porto Alegre: Artes Médicas.

Hernández, Fernando. 1998. A Organização do Currículo por Projetos de Trabalho: O Conhecimento é um Caleidoscópio. Porto Alegre: Artmed.

Juanola, Roser, e Anna Colomer. 2005. "Museus y Educadores: Perspetivas y Retos de Futuro." In La Mirada Inquieta: Educación Artística y Museos, editado por Ricard Huerta, e Romà de la Calle, 21-4 0 . Valéncia: Universitat de València.

Martins, Mirian Celeste, e Gisa Picosque. 2008. Mediação Cultural para Professores Andarilhos na Cultura. Rio de Janeiro: Instituto Sangari.

Ortiz, Renato. 2003. Cultura Brasileira e Identidade Nacional. São Paulo: Brasiliense.

Ramos, Francisco Régis Lopes. 2004. A Danação do Objeto: O Museu no Ensino de História. Chapecó: Argos.

Schlichta, Consuelo. 2009. Arte e Educação, Há um Lugar para a Arte no Ensino Médio? Curitiba: Aymará.

Silva, Susana Gomes da. 2007. "Enquadramento Teórico Para uma Prática Educativa nos Museus." In Serviços Educativos na Cultura. Coleção Públicos 2, editado por Sara Barriga, e Susana Gomes da Silva, 57-66. Porto: Setepés. http://pt.slideshare.net/JDLIMA/coleco-pblicos-servios-educativos\#. 


\section{NOTAS}

1. Professoras e professores de arte não estão todo o tempo com os estudantes, a professora regente como acompanhante é o ideal.

2. B. Freire diz: «Quando um professor se apropria, ainda que parcialmente, dos recursos que o museu oferece e cria com eles diferentes composições, associando a visita a outras estratégias de ensino, ele está sendo sujeito de uma prática que o museu aceita com dificuldade» $(1996,20)$.

3. A questão da autoridade nos conhecimentos específicos da linguagem artística visual é um tema que mais à frente aprofundo tomando as ideias de Arendt (2005).

4. Para Arendt (2005) o mundo é «velho, préexistente e construído pelos vivos e mortos», um mundo novo apenas ao imigrante e ao recém-nascido, os indivíduos que terão de entrar nesse mundo público. Pensando nos Estados Unidos e na sua ideologia igualitária, é que Arendt falará sobre a crise. Segundo ela, nessa ideologia crianças e adultos precisam ser tratados da mesma forma. No caso do imigrante, ele teria de assumir a cultura da nova nacionalidade para nela ser introduzido; no caso da criança, ela teve de ser igualada ao adulto e para isso teria sido inventado o mundo da criança. A causa da crise viria dessa emancipação prematura e pela importação de um modelo novo de educação, ainda em teste na Europa naquele momento, instituído indiscriminadamente na América. Esta educação moderna teria trocado a transmissão de conhecimentos pelo ensino por atividades, acreditando que somente se pode aprender o que se faz, tornando-se inculcação de habilidades e pondo de lado o ensinamento dos saberes da tradição, do mundo velho. Essa emancipação prematura teria posto a crise, a perda do papel de autoridade do adulto/professor sobre o mundo público e a transmissão da tradição.

5. O autor utiliza o termo linguagem de forma genérica, no sentido de conjunto de ideias pertinentes a um campo e grupo que estrutura limites de poder, não se refere à arte como linguagem, enumera nessa categoria: «o inglês, a matemática, a física, o teatro ou qualquer outra».

6. Os questionários encontram-se em poder do autor.

\section{RESUMOS}

A visita de grupos escolares a museus, apesar de incentivada pela sociedade, requer do/da professor/a uma série de preparativos. Além de dificuldades a serem vencidas na escola, os docentes vivem durante essa visita uma tensão advinda de julgamentos e da pressão institucional, que, sem afirmar, elege como seu público os conhecedores da arte. A perspetiva política defendida como ato educador no texto parte de ideia de Arendt: da escola como prática ao exercício da vida pública, articulando, então, o ensino da arte na escola - caráter privado, ao museu, locus da arte; ao entender a ação docente como política, trago as considerações de Giroux sobre o caráter intelectual do educador. A reflexão apresentada parte do contexto brasileiro da educação, que na relação escola e museu, com raras exceções, ainda é pouco desenvolvida.

The visit of school children to museums is encouraged by society; for the teacher, however, it requires a series of preparations. In addition to the difficulties presented by the physical demands of bringing students from the school to the museum, teachers experience museum- 
originated tensions from judgments and institutional pressure which, without affirming it, prefer, among its audience, those 'in the know' as far the contents of a collection are concerned. The educator's act of political perspetive defended in this paper is linked to Arendt's idea that the school operates as a practice to public life, articulating the private teaching art at school to the museum space, locus of art. By understanding teaching as a political act, I reference Giroux's concepts about the intellectual character of a teacher. This reflection is based on the context of Brazilian education, still underdeveloped when it comes to articulate the interaction between school and museum.

\section{ÍNDICE}

Keywords: mediation, school public, museums education, learning, art education Palavras-chave: público escolar, museus e educação, mediação, educação artística, aprendizagem

\section{AUTOR}

\section{LUCIANO PARREIRA BUCHMANN}

Professor assistente do curso de licenciatura em Artes Visuais (Universidade Estadual do Paraná, Campus Faculdade de Artes do Paraná). Mestre em Arte (2007) pela Universidade do Estado de Santa Catarina. Participa no grupo de pesquisa Arte, Ensino e Formação Continuada. Interessado na relação entre o museu e o ensino da arte, publicou a Coleção Preparação, abordando a visita de grupos escolares a museus de arte em Curitiba (Paraná, Brasil). lucianobuchmann@gmail.com 